\title{
Conflitos interescalares: o local e o metropolitano na gestão do território
}

\author{
Intersected conflicts: the local and the metropolitan in territory management
}

Alexsandro Ferreira Cardoso da Silva ${ }^{[0]}$, Lindijane de Souza Bento Almeida ${ }^{[a]}$, Glenda Dantas Ferreirra ${ }^{[b]}$, Raquel Maria da Costa Silveira ${ }^{[0]}$

[a] Universidade Federal do Rio Grande do Norte (UFRN), Natal, RN, Brasil
[b] Universidade Federal da Paraíba (UFPB), João Pessoa, PB, Brasil

\section{Resumo}

Desde a Constituição Brasileira de 1988, a criação das Regiões Metropolitanas é atribuição das Assembleias Legislativas dos estados. Por outro lado, os municípios estão diretamente ligados às lógicas cotidianas do local e, ao mesmo tempo, são inseridos em uma escala supralocal de poder e governança. Essa aparente contradição é reveladora das disputas interescalares do poder sobre o Território, expressas na busca por capturar planos, programas e projetos de desenvolvimento local com justificativas supralocais. Objetiva-se, aqui, entender de que modo a disputa por projetos territoriais leva em conta o conflito interescalar, articulando o Planejamento e a Gestão urbana no território metropolitano. Para tanto, a pesquisa destacou algumas ações que revelam as formas de centralização e descentralização do Planejamento e da Gestão na Região Metropolitana de Natal, RN, Brasil, na última década (2006-2016). Nesse sentido, foi realizada uma pesquisa de cunho bibliográfico relacionada ao planejamento e à gestão territorial, bem como à descentralização e à governança colaborativa e à pesquisa documental de leis e decretos, assim como a leitura de projetos urbanos locais com incidência metropolitana.

Palavras-chave: Regiões metropolitanas. Governança colaborativa. Planejamento e gestão territorial.

\section{Abstract}

Since the Brazilian Constitution of 1988, the creation of Metropolitan Regions is attributed to the Legislative Assembly of the States. On the other hand, the municipalities are directly linked to the local daily logics and, at the same time, are inserted in a supra-local scale of power and governance. This apparent contradiction reveals an interscalar power struggle over territory, expressed in the quest to capture local development plans, programs, and projects with supra-local justifications. This study aims to understand how the dispute for territorial projects takes into account the interscalar conflict, articulating Urban Planning and Management in the metropolitan territory. The research highlights a set of instruments (plans, projects) that reveals the forms of centralization and decentralization of Planning and Management, in the Metropolitan Region of Natal, RN,

AFCS é arquiteto e urbanista, doutor em Arquitetura e Urbanismo, e-mail: alexsandroferreira@hotmail.com LSBA é cientista social, doutora em Ciências Sociais, e-mail: almeida.lindijane@gmail.com GDF é cientista social, doutora em Arquitetura e Urbanismo, e-mail: glenda.dgp@hotmail.com RMCS é advogada e gestora de políticas públicas, doutoranda em Ciências Sociais, e-mail: raquelmcsilveira@hotmail.com 
Brazil, in the last decade (2006-2016). We performed a bibliographical research on territorial planning and management, as well as decentralization and collaborative governance. We also performed a documentary research of laws and decrees, and local urban projects with metropolitan incidence.

Keywords: Metropolitan regions. Collaborative governance. Territorial planning and management.

\section{Introdução}

A busca de uma explicação apropriada sobre o papel da espacialidade - enquanto objeto e ao mesmo tempo conceito - é uma das contribuições fundamentais daqueles que abordam a Teoria Urbana comprometida com certa Teoria Social, especialmente aquelas críticas ao capitalismo contemporâneo. De modo rico e diverso, tal contribuição pode ser encontrada nos trabalhos seminais de Edward Soja (1993) e Mark Gottdiener (2010) quando discutem o papel do Espaço na sociedade contemporânea, ou melhor, no discurso acadêmico sobre a reestruturação econômica e seus impactos no Social e no Espacial.

Concentração e desconcentração, local e global, entre outras, avançam ou recuam sobre o Espaço buscando explicar os padrões de estruturação e distribuição das atividades produtivas — impactadas pela acumulação flexível ou pela crise social advinda dessa flexibilidade. Neil Brenner $(2001,2004,2013)$ auxilia àqueles interessados em encontrar um nexo nesse debate crítico nas Políticas Públicas territoriais ao analisar o papel do Estado na promoção, produção e ampliação dos ambientes regionais de negócios (competição ou inserção econômica) em um cenário de crise fiscal. Diz Brenner (2013, p. 205) que as pesquisas contemporâneas primam por “[...] repensar conceitualmente a questão urbana de forma a relacioná-la de modo mais direto com diversos processos de reescalonamento supraurbanos".

Dentre as manifestações socioespaciais envolvidas nas formas de acumulação do capital ou na resolução de crises conjunturais (fiscal, de produção etc.), o conceito de política escalar ganha expressão não apenas no sentido estrito (normativo, prescritivo), mas sobretudo como arena de disputas (conflitivas ou colaborativas) - protagonista nos destinos do Território (com relações de poder sobre o Espaço) ${ }^{1}$

\footnotetext{
${ }^{1}$ Claude Raffestin (1993, p. 143-144) comenta que "O território, nessa perspectiva, é um espaço onde se projetou um trabalho, seja energia e informação, e que, por consequência, revela relações marcadas pelo poder. 0 espaço é a 'prisão original', o território é a prisão que os homens constroem para si”.
}

em um dado contexto de reestruturação capitalista. Neste artigo, uma fração conceitual e empírica do Território - a Região Metropolitana — foi definida como objeto de investigação sobre seu papel como região de investimentos e produção de espaços econômicos vis-à-vis sua definição institucional de planejamento e gestão, aqui, em especial, da Região Metropolitana de Natal (RN).

Defendemos, neste artigo, que uma contradição entre a Metrópole (enquanto entidade institucional) e a Cidade (enquanto expressão física das políticas urbanas) é reveladora de disputas interescalares de poder, expressas na busca por capturar planos, programas e projetos de desenvolvimento local com justificativas de cooperação regional. Isto é, as obras e as intervenções físico-territoriais passam a carecer de ferramentas de governança (políticas, técnicas e sociais), na perspectiva do território, das escalas e do espaço, que deem substância a um modelo de gestão efetivo.

Desse modo, aventamos como hipótese que políticas de gestão metropolitana que só trabalhem a governança metropolitana - sem considerar as relações interescalares (microlocal, local, regional, nacional etc.) e de colaboração, apresentam maior dificuldade de implementação.

Tal preâmbulo nos permite lembrar quão difícil é abordar a formação regional brasileira sem considerar as características espaciais (do território "usado"2) nessa definição política. A institucionalização e os ritos associados a ela, de certo modo, direcionam o debate sobre as RMs em um molde que desconsidera as especificidades locais e regionais, baseando-se na capacidade política de arranjos, no governo estadual, na Assembleia Legislativa e nos municípios, como elementos de forte adesão (contra ou a favor) e não de cooperação - articulação e superação de dificuldades comuns.

\footnotetext{
${ }^{2}$ Cf. definição em Milton Santos (2000), em entrevista a Odeth Seabra, M. de Carvalho e J. Corrêa Leite, assim como em Santos (2004, p. 34), a Jesus de Paula Assis e M. E. Sposito.
} 
Veremos adiante dois ensaios dessa problemática; um pelo viés da governança colaborativa como possível tratamento das questões políticas, outro pelo viés da aplicação de uma lógica que reconheça o "jogo de escalas" quando abordamos o tema metropolitano.

\section{Do local ao metropolitano: breves notas sobre o problema das escalas}

A inserção da Metrópole enquanto uma escala regional, neste texto, é ponto de partida para definição do conflito interescalar manifesto nas políticas públicas territoriais. Não é desconhecido o problema de aplicação do próprio conceito de escala enquanto fenômeno, ou como modelo de análise e elemento de ação, conforme sintetizou Marcelo Souza (2013, p. 179); ou do sentido de ajuste espacial sob o capitalismo, conforme refletido por David Harvey (2006), quando discute acerca da contradição do capital que, ao mesmo tempo, se torna fixo e é impelido a circular constantemente, indicando que a "[...] tarefa da teoria espacial, no contexto do capitalismo, consiste em elaborar representações dinâmicas de como essa contradição se manifesta" (Harvey, 2006, p. 145). Em boa medida, os trabalhos seminais de Neil Smith $(1988,2000)$ e Carlos Vainer (2002) trazem as escalas como um problema de definição política, mais do que geográfica ou cartográfica, como uma forma de política escalar.

Desse modo, partimos de um conceito de escala como manifestação de uma representação do Território delimitado por uma geografia particular e que se impõe enquanto arranjo político-institucional dentro de um quadro legal, econômico e social. Dito de outro modo, a "escala local" significará a manifestação concreta da Cidade enquanto o regional torna-se a representação formal da Metrópole.

Tal definição é de ordem metodológica, em princípio, pois não relativiza a dimensão física da Metrópole (que é crescente e dramática), apenas define que uma gestão metropolitana deve estabelecer uma lógica articulada, isto é, física e política. Mais à frente, pretendemos integrar essa lógica à expressão material da Metrópole - expressa em grandes projetos, por exemplo.

Outra conceituação possível do local (dentre várias) é Urbano ou Metropolitano como adjetivação desse urbano ampliado; nesta proposta, o urbano insurge como conteúdo que perpassa tanto a Cidade quanto a Metrópole ${ }^{3}$, por sua capacidade de interpretação e conjunção de diferentes escalas - do microlocal ao regional, sendo que perseguiremos o conflito escalar no âmbito de uma política escalar.

Um ponto seguinte a destacar é aquele que trata dos conflitos; não há conflito entre as escalas, mas sim entre as diferentes representações de poder que se manifestam, sobretudo, espacialmente pela escala do Local e da Metrópole. Que o sentido de contradição está presente torna-se um pressuposto do desenvolvimento geográfico desigual pelo qual o espaço é tratado (Smith, 1988; Harvey, 2006). Desse modo, conflitos são as disjunções e aproximações interescalares reveladoras de estratégias políticas de poder sobre dado território, ora como projeto, ora como estratégia. A aproximação entre tais definições conceituais e as estratégias do Estado revela "[...] a importância e a evolução das funções do Estado (locais, regionais, nacionais e supranacionais), [e] do desenvolvimento geográfico desigual [...]" (Harvey, 2006, p. 144).

Revelador, também, dessa "questão escalar" é a existência da Região Metropolitana, no Brasil, no aparato estatal e das políticas públicas. 0 primeiro problema a considerar é a definição política-administrativa da metrópole na legislação nacional. Na Constituição de 1967 (Brasil, 1967), modificada pela Emenda Constitucional n. 1 de 1969, vemos que a ênfase do artigo 164 recaiu na funcionalidade desempenhada pela Região Metropolitana e na capacidade de realização de serviços comuns (saneamento, transportes, uso do solo), mediadas por um Plano de Desenvolvimento Integrado. A definição desses itens está ligada à necessidade de um planejamento municipal comum, mas sem a criação de um espaço ou definição de um novo território específico. Apenas na Lei Complementar Federal n. 14/1973 a definição de quais municípios seriam metropolitanos ocorreu, mas, novamente, sem uma caracterização desse território. Que os municípios podem ser organizados em uma Região Metropolitana estava claro. Mas quais elementos fundamentavam essa organização? (Brasil, 1973).

Antes da Lei Complementar n. 14/1973 havia uma discussão no núcleo do governo federal sobre

\footnotetext{
${ }^{3}$ Nesse sentido, Maria Adélia Aparecida de Souza comenta que "[...] cidade é o mundo da forma, da materialidade. 0 urbano é o complexo significativo da expressão territorial do modo de produção, é abstrato, mundo das funcionalidades - é a expressão da dominação, mas pode ser também da libertação" (Souza, 2006, p. 36).
} 
a capacidade das Regiões Metropolitanas serem ou não entes políticos e administrativos - podendo tributar, executar e definir uma agenda pública própria, por exemplo. Venceu, nos anos de 1967 e 1969 (Constituição e Emenda Constitucional) e na Lei Complementar n. 14, a tese de que as RMs são elementos meramente administrativos, espaços vazios de poder territorial que permitem a cooperação visando interesses comuns - o poder seria delegado pela União aos municípios.

A Constituição Federal de 1988, por seu turno, voltou a repetir a ênfase política-administrativa e não territorial, mas agora retirando da União e passando aos governos estaduais o poder de criação das RMs. Seu artigo 25 , no parágrafo 3ㅜㅡ. agrupa municípios para "[...] a organização, o planejamento e a execução de funções públicas de interesse comum" (Brasil, 1988). Venceu, portanto, a máxima de Eros Roberto Grau de que as RMs são

"[...] meros instrumentos de institucionalização do planejamento, havendo de preservar, assim, elasticidade suficiente para que sirvam eficiente e dinamicamente ao seu fim primordial" (Grau, 1972, p. 217).

Um segundo problema a ser considerado é o reposicionamento do debate sobre as escalas ocorrido nos anos 1990, logo após a Constituição de 1988. De um lado, a ênfase no municipalismo como bandeira da redemocratização; por outro, os sinais da globalização como força econômica que se instalava na América Latina. Esse duplo movimento local-global conduziu a análises que permitiram a rediscussão da "questão escalar", mas agora situada no posicionamento localregional-global - novamente tirando o foco de um espaço em particular (a Metrópole) e colocando mais ênfase na relação entre os espaços no Território. Ora, se isso era verdade (a questão interescalar sobredetermina a questão escalar), o debate sobre o "poder das escalas" considerava adesão (ou não) ao Global e suas ingerências a partir de um modelo de competitividade que permitisse acessar os recursos (financeiros, culturais, estratégicos etc.) de modo mais facilitado.

É desse modo que Global e Local estabelecem uma dupla interface, deixando em segundo plano o regional enquanto território. Borja \& Castells (2004) surgem como autores que associam o poder do local - e das cidades, na capacidade de atrair e competir por fluxos de capital, mercadorias e bens, por exemplo, considerando a competividade econômica e a integração cultural. No Brasil, a reestruturação do Estado proposta no primeiro governo de Fernando Henrique Cardoso (1994-1998), a ênfase no municipalismo e a restrição fiscal criaram um sentimento de que a escala do local se constituía no espaço preferencial da luta política. Mas o que é o local? Conforme questiona Vainer (2002, p. 18):

Até que ponto é possível imaginar que as realidades a que se remete a noção de local sejam minimante comparáveis ou redutíveis ao mesmo conceito de formações sócio-históricas e territoriais tão distantes quanto a comuna francesa, o county ou a city [norte] americana, o município brasileiro, a aldeia asiática, etc.?

E nós poderíamos acrescentar as Regiões Metropolitanas. 0 esvaziamento da questão escalar na legislação nacional — como vimos acima, associado a um fortalecimento do debate local-municipal - levou a uma percepção política das RMs como entidades de fácil institucionalização e sem responsabilidade socioterritorial. Receptáculos frios e distantes do local e silenciosas em termos do Global, as RMs puderam ser expandidas nos anos 1990 e 2000 em diversas formações e arranjos, por Assembleias Legislativas estaduais pouco atentas à real capacidade transescalar ${ }^{4}$.

De modo aparente, certa polarização se processou entre uma tendência de análise do Local como escala prioritária do Planejamento (localistas, municipalistas, estratégicos etc.) e demais estudos com ênfase no papel da Rede Urbana como definidora maior do território nacional. A armadilha dessa dupla relação Local-Rede é a configuração de um território dado como entidade descolada dos conflitos e contradições do cotidiano, isto é, certa "naturalização" da Rede como entidade informativa (sobre o que é o território nacional), associada a uma baixa visão crítica do Regional, do Local e da Cidade como entidades dinâmicas nas quais tais contradições encontram guarida.

0 arranjo sofisticado das análises microeconômicas e demográficas atuais, por seu turno, deixa escapar a apreensão do sentido à metrópole dado ainda pela SERFHAU (anos de 1960 e 1970) de "comunidade socioeconômica" e sua proximidade com as

\footnotetext{
${ }^{4}$ Aqui nos apropriamos da citação de Carlos Vainer: "Antes de serem os campos possíveis de ação política, as escalas constituem, portanto, os resultados, sempre contestáveis e contestados, de embates, assim como o são as relações interescalares e a predominância de uma escala sobre as demais" (Vainer, 2002, p. 25).
} 
definições de "atores locais", isto é, grupos e seres que se fixam e circulam pelo território à procura de novas oportunidades. É nesse sentido que refletem Brandão et al. (2006, p. 197) quando afirmam que "Prepondera aí, portanto, uma visão de ambiente não construído socialmente, mas de território como um pressuposto dado naturalmente".

As RMs poderiam, em outro contexto, assumir funções estratégicas dessa mediação entre Local e Global, desde que seus pressupostos dessem menor ênfase às "funções ou serviços comuns" e passassem a considerar o desenvolvimento territorial atrelado à construção de um espaço urbano-regional articulado. Isso exigiria a redefinição do "interesse comum" para um espaço usado, vivo, dinamizado de forma conjunta (Santos, 1996).

Para superar - ou atenuar - tal impasse ou conflito escalar é importante registrar algumas inovações no planejamento urbano e regional brasileiro, como a Lei Federal 11.107/2005 (Brasil, 2005), que criou a possibilidade de Consórcios Públicos no Brasil. Nem locais, nem regionais, tais consórcios podem materializar o "interesse comum" descolado de uma regionalização prévia (ou institucionalmente criada), buscando a ligação local-local de modo efetivo. Na prática, ao Consórcio Público foi dada a capacidade de atuar como ente político-administrativo-territorial com mais poderes do que as RMs; seu artigo $2^{\circ}$, no parágrafo $1^{\mathfrak{0}}$, estabelece sua capacidade de firmar convênios, contratos, desapropriar bens e até cobrar taxas. Os Consórcios Públicos foram tomados como novo alento à capacidade de formação de parcerias e cooperação intermunicipais, agilizando processos bloqueados na escala metropolitana. Então, por que não cooperam tais metrópoles?

Sol Garson (2009) lança alguma luz sobre essa questão quando afirma que a passagem aos estados da prerrogativa da criação das RMs resultou na pouca capacidade de aproximação, entre os entes locais, de certa dinâmica política e econômica, resultando em atores diversos, pouco coesos, grandes e heterogêneos e, portanto, difíceis de cooperar. Outro fator-chave nessa dificuldade de cooperação é a grande diferença na capacidade fiscal e tributária de fazer frente aos, novamente, problemas de interesse comum (Garson, 2009, p. 197).

Por fim, surgiu recentemente o Estatuto da Metrópole (Lei Federal n. 13.089/2015, Brasil, 2015) como uma nova proposta de governança metropolitana.
Será que a questão do Poder Local e da Capacidade Colaborativa assumem novos papeis em uma escala efetiva de planejamento e gestão? Quais novos caminhos estão dados ao território metropolitano a partir de um Estatuto legal que se pretende definidor e regulamentador do artigo 25 da Constituição Federal?

No referido Estatuto, o primeiro destaque que nos interessa, na questão escalar, é a definição um pouco mais precisa sobre o que é uma Região Metropolitana; não apenas a atribuição de funções, mas, sobretudo, uma forma territorial que assume características de aglomerado, metrópole, capital regional e região. Embora não desça em detalhes demográficos, essa passagem do Estatuto da Metrópole sinaliza uma abordagem escalar.

Um segundo destaque é a associação entre a metrópole e o espaço ocupado, construído. Alguns instrumentos previstos para isso estão citados no artigo 9o do Estatuto da Metrópole como, por exemplo, Planos de Desenvolvimento Integrado, Planos Setoriais, Operações Urbanas, entre outros; tais instrumentos, por seu turno, necessitam da inscrição no território usado - da cidade ou da metrópole, cuja aplicação efetiva dar-se-á em uma dada localização — do micro local até o regional. Mas como coordenar tais instrumentos associado a uma gestão interfederativa, isto é, como articular o poder sobre o território com a manifestação dos fenômenos urbanos existentes? A aposta em uma governança interfederativa, por si só, não encontra meios político-administrativos novos no Estatuto da Metrópole, mas acredita em uma pactuação expressa no Plano de Desenvolvimento Urbano Integrado na metrópole.

Diante do exposto, como vimos acima, a "questão escalar" ainda é um tema importante do debate sobre a inscrição metropolitano versus local no quadro do planejamento regional brasileiro; se há avanços, em um sentido da normatização, não vemos também uma definição mais específica do tratamento escalar no território nas questões de singularidade metropolitana ou urbana, para além das indicações legais. É nesse sentido que consideramos importante trabalhar o modelo de governança ao lado de uma definição escalar voltada às Regiões Metropolitanas. Na sequência, apresentaremos uma discussão acerca do conceito de governança a fim de que, em momento posterior, possamos estabelecer uma relação mais próxima entre teoria e prática. 


\section{Governança colaborativa na escala metropolitana: algumas notas}

No presente trabalho partimos da premissa de que o conceito de governança é basilar para compreendermos questões relacionadas às disputas interescalares de poder sobre o território, expressas na busca por capturar planos, programas e projetos de desenvolvimento local com justificativas supralocais. Com relação à noção de governança, Clementino \& Almeida (2015) retomam discussão realizada por Reis (1994), afirmando que governança se refere à capacidade de governo. Em outras palavras, o conceito diz respeito ao exercício do ato de governar tomado em uma perspectiva dinâmica, além de incorporar elementos como capacidade de coordenação, de implementação e também capacidade de produzir credibilidade com os elementos que a constituem, os quais são interdependentes (Reis, 1994, p. 198 apud Clementino \& Almeida, 2015, p. 206). Para Frey (2012, p. 88):

Não por acaso, a noção de governança ganhou importância e foi inicialmente concebida como uma abordagem teórica e analítica para compreender as novas formas e práticas de articulação político-administrativa que surgiram relacionadas, por um lado, à influência política crescente da União Européia e, por outro, ao processo de metropolização.

É como base nessa construção teórico-analítica, portanto, que procuraremos iluminar a reflexão acerca de fenômenos empíricos manifestos na escala metropolitana. Com relação a essa escala, destacamos a sua crescente relevância na estruturação do processo de desenvolvimento econômico, aspecto esse que torna a análise da governança algo de extrema relevância. Isso porque as múltiplas e complexas dinâmicas e processos existentes na escala metropolitana exigem mais do que uma racionalidade para lidar com os dilemas da ação coletiva, uma vez que se faz necessária a integração e a coordenação da ação intermunicipal de forma horizontal e vertical (Frey, 2012).

Além disso, ressaltamos que a governança colaborativa se apresenta como uma vertente teórico-conceitual fundamental que marca a importância dos processos políticos, do relacionamento dos atores sociais e políticos e das instituições, a fim de que se possa alcançar uma boa gestão metropolitana. Para Ansell \& Gash (2007, p. 2):
A governança colaborativa seria uma estrutura de governo na qual uma ou mais organizações públicas conseguem diretamente engajar atores não estatais em um processo de tomada de decisões coletivo, que é, formal, orientado pelo consenso e deliberativo e tem por objetivo fazer ou implementar políticas públicas, gerenciar programas ou bens públicos.

O conceito de governança colaborativa parte de uma perspectiva de análise e observação que inclui a capacidade de coordenação e cooperação (arranjos colaborativos em diferentes níveis), por meio da criação de redes internas e externas entre Estado, mercado e sociedade, empenhados na intensificação da ação estatal, respeitando democraticamente seus constrangimentos e reduzindo os conflitos constantes através da consolidação de pactos de planejamento e gestão (McGee, 2010; Neves et al., 2010).

No seio dessa discussão, um aspecto relevante é a inexistência de um sistema de governo metropolitano que sinalize soluções comuns aos conflitos escalares. As Regiões Metropolitanas compõem um arranjo político-institucional, áreas de enormes contradições e dinâmicas sociais - potencialidades e vulnerabilidades acumuladas. Esse rico e complexo quadro necessita de políticas públicas não apenas sinalizadoras mas efetivas (na forma da implementação de programas e projetos) da Política Urbana e Regional.

Em decorrência disso, além da falta de padronização na forma de planejamento e de gestão nos governos estaduais nas metrópoles brasileiras ocorrem, simultaneamente, dois processos: um de integração formal (legal-institucional) e outro de integração funcional, e ambos colocam limites e possibilidades à integração plena e ao fortalecimento da governança colaborativa. Isso porque as condições técnicas, políticas e sociais se apresentam diferenciadas nos municípios que compõem as regiões metropolitanas, implicando em capacidades contributivas e raios de ação também diversos, o que justifica as dificuldades no estabelecimento de canais de cooperação horizontal e vertical.

Apesar dos avanços legais que subsidiam o planejamento e a gestão das cidades, com base no Estatuto da Cidade e no Estatuto da Metrópole, mantém-se oportuna a inclusão do conceito de autonomia de gestão na análise dos desafios da governança colaborativa e sua capacidade de se tornar, também, colaborativa, uma vez que interfere na organização e 
dinâmica das cidades, dada a dependência financeira da maioria dos municípios brasileiros em relação aos repasses da União ${ }^{5}$, ou seja, em torno das transferências obrigatórias, que cobrem os gastos da administração pública municipal, inclusive a prestação dos serviços sociais básicos previstos constitucionalmente.

Em que pese o processo de aprendizagem e reaprendizagem democrática, o nosso sistema político (partidário-eleitoral) não mudou o "jogo político" presente nas arenas decisórias que tratam das transferências voluntárias e/ou do acesso a operações de crédito aos municípios, que são as fontes de financiamento que os municípios têm para poder realizar obras e investimentos em infraestrutura urbana e social.

Aparentemente, as negociações políticas realizadas a partir de interesses político-eleitorais, em detrimento da qualidade e viabilidade técnica dos projetos apresentados, sobrevivem e se adaptam a contextos democráticos porque são utilizadas como eficiente estratégia política adotada por governantes, respaldada na desigualdade social e, acima de tudo, no quadro de pobreza dela decorrente.

Diante do exposto, evidenciamos que, na prática, os processos e as dinâmicas dos entes, em face dos processos de negociação política, tem se distanciado cada vez mais daquilo que a recente literatura acerca da governança colaborativa tem destacado como relevante e necessário. Ou seja, que, na escala metropolitana, processos de negociação política podem (e devem) gerar cooperação, uma vez que problemas comuns precisam ser resolvidos, num primeiro momento, no plano da política, dada a ausência de uma esfera de governo metropolitana. Dessa forma, a existência de um continuado aprendizado político que seja capaz de atenuar a competição entre municípios, fortalecendo a visão regional, se apresenta como extremamente necessário (Ferreira, 2005).

Em linhas gerais, podemos dizer que a falta de ação coletiva entre os governos municipais para

\footnotetext{
${ }^{5}$ A propagada autonomia de gestão é amplamente discutida na sociedade brasileira pós divulgação dos resultados de pesquisas realizadas seja na academia, seja no governo, que demonstram a reduzida capacidade político-administrativa e a limitada autonomia financeira de mais de 4 mil dos 5.570 municípios brasileiros, muitas vezes tornando-os reféns dos recursos obtidos por meio das transferências voluntárias, o que tem dificultado a consolidação de um novo modelo de gestão da política pública urbana pautado na implementação de políticas públicas desenhadas de forma cooperativa e colaborativa.
}

subsidiar a resolução dos problemas metropolitanos pode, em alguma medida, ser explicada pela relativa ausência de um interesse coletivo expresso em uma agenda metropolitana, em grande medida resultante da fragilidade do próprio arranjo institucional ou da capacidade fiscal-financeira e das estruturas de planejamento e gestão dos entes que compõem os espaços metropolitanos. Como chama atenção Garson (2005, p. 6):

A composição das fontes de financiamento desempenha um papel fundamental para a avaliação da sustentabilidade em longo prazo e da possibilidade de cooperação entre municípios para fomentar a economia urbana através de seus efeitos multiplicadores: projetos de longo prazo só poderão ser desenvolvidos em um ambiente de cooperação caso os participantes disponham de garantia de fontes de recursos que lhes permitam assumir compromissos.

Essa é uma parte do problema. A outra, de modo geral, dá-se pelo pouco esforço para tratar esse território a partir de uma lógica de conflitos escalares.

A partir desse debate, discutiremos, a seguir, o processo de constituição da Região Metropolitana de Natal, como um caso formal, mas não colaborativo. Tal evidência se mostra mais clara quando discutimos questões relacionadas, de um lado, ao Estatuto da Metrópole, do ponto de vista normativo, e, de outro, ao Aeroporto Internacional de São Gonçalo do Amarante e ao Aterro Sanitário Metropolitano, casos empíricos escolhidos no presente estudo.

\section{Região Metropolitana de Natal: a (difícil) articulação entre escalas, planos, programas e projetos}

A institucionalização da Região Metropolitana de Natal (RMN) ocorreu no ano de 1997, por meio da Lei Complementar Estadual (LCE) n. 152 (Rio Grande do Norte, 1997). Em sua composição original, a RMN foi formada pelos municípios de Macaíba, Extremoz, São Gonçalo do Amarante, Ceará-Mirim, Parnamirim e Natal. Posteriormente, os municípios de São José de Mipibú, Nísia Floresta (LCE n. 221/2002, Rio Grande do Norte, 2002), Monte Alegre (LCE n. 315/2005, Rio Grande do Norte, 2005) e Vera Cruz (LCE n. 391/2009, Rio Grande do Norte, 2009) foram inseridos na região. 
Mais recentemente, Maxaranguape (LCE n. 485/2013, Rio Grande do Norte, 2013), Ielmo Marinho (LCE n. 540/2015, Rio Grande do Norte, 2015a), Arês e Goianinha (LCE n. 559/2015, Rio Grande do Norte, 2015b) foram acrescentados, totalizando 14 municípios.

Tal adesão de novos municípios, entretanto, está mais relacionada com o interesse político do que, considerando a ênfase deste artigo, com a busca por soluções territoriais compartilhadas para problemas comuns. Esse aspecto, por sua vez, tende a gerar um enorme distanciamento entre a metrópole institucionalizada pelo governo estadual e a metrópole funcional (Natal-Parnamirim-São Gonçalo do Amarante) ${ }^{6}$.

Na contramão do avanço do número de membros, as discussões em torno do planejamento e da gestão da RMN seguiram lentamente, permeadas por questões políticas que, nitidamente, punham em primeiro plano o interesse local, utilizando o "discurso" integrador metropolitano.

Assim, raros foram os encontros para debates formais em torno de questões metropolitanas. Uma das eventuais coalizões formadas, e que poderia ter dado início a uma conjunção perene em prol de um planejamento territorial comum, foi a realização de convênio entre os municípios de Natal e Ceará-Mirim, em 2004, para a criação de um aterro sanitário.

A criação do denominado "aterro metropolitano" trouxe a possibilidade de planejamento de soluções compartilhadas para a gestão integrada de resíduos sólidos. Ocorre que, desde a sua construção até os dias atuais, o aterro metropolitano nunca teve, de fato, um arranjo que possibilitasse a afirmação da existência de um planejamento comum. Prova disso é o fato de que, em 2012 - quando a RMN já contava com 10 municípios, o referido aterro recebia os resíduos de 8 municípios, sendo apenas 6 deles entes formadores da RMN (SEMARH, 2012). Desse modo, destinavam seus resíduos ao aterro metropolitano os municípios de: Natal, Ceará-Mirim, Parnamirim, Ielmo Marinho, São Gonçalo do Amarante, Extremoz, Rio do Fogo e Macaíba. Desses, apenas Natal, Ceará-Mirim, Parnamirim, São Gonçalo do Amarante, Extremoz e Macaíba eram municípios metropolitanos. Os demais municípios que formavam a RMN, em 2012, (São José de Mipibú, Nísia Floresta, Monte Alegre e Vera Cruz), por sua vez, optavam, naquele momento, por soluções individualizadas para a destinação final dos resíduos.

\footnotetext{
${ }^{6}$ Para maiores detalhes, ver Clementino \& Ferreira (2015).
}

A elaboração do Plano Estadual de Gestão Integrada de Resíduos Sólidos (PEGIRS), em 2012, veio apenas confirmar o status do aterro "metropolitano" enquanto disposição final de resíduos de entes locais, sem que existisse um compartilhamento do planejamento (SEMARH, 2012). Assim, o governo do Rio Grande do Norte apresentou, no referido documento, uma regionalização distinta da formação institucional da RMN.

Conforme o plano, o aterro metropolitano deveria receber resíduos provenientes de parte dos municípios formadores da RMN (Ceará-Mirim, Extremoz, Macaíba, Natal, Parnamirim, São Gonçalo do Amarante), além de municípios que não compunham ainda a RMN (Ielmo Marinho, Maxaranguape - incorporados à RMN apenas em 2013 e 2015, respectivamente). Naquele contexto, os demais entes metropolitanos foram posicionados em regionalizações distintas, devendo buscar soluções consorciadas junto a outros municípios. Desse modo, Vera Cruz, Nísia Floresta, São José de Mipibu e Monte Alegre (que já faziam parte da RMN à época da elaboração do plano) compunham a Região Agreste, devendo apresentar pactuação diferenciada com municípios que não formam a RMN.

A justificativa apresentada pelo governo estadual para a elaboração da regionalização está pautada nas características dos municípios e na proximidade entre as cidades. Destaque-se que o plano estadual foi atualizado, em 2016, deixando, novamente, de contemplar todos os municípios da RMN na composição do aterro metropolitano. 0 fato é que a existência de uma regionalização distinta para entes integrantes de uma região metropolitana, além de descompassar o planejamento e a gestão de problemas comuns, revela um território desarticulado.

O que se observa, portanto, é o predomínio de planos, programas e projetos que, apesar de possuírem um caráter metropolitano-local — sobretudo porque incidem e promovem alterações nas dinâmicas socioterritoriais e econômicas na escala da cidade e da área metropolitana - são tratados como iniciativas apenas locais. Outro caso que pode ser utilizado para elucidar tal afirmação é o Aeroporto Internacional Aluízio Alves, localizado em São Gonçalo do Amarante.

O Aeroporto Internacional Aluízio Alves foi inaugurado em 2014, viabilizado por uma das primeiras Parcerias Público-Privadas (PPPs) de aeroportos no Brasil, concedendo-se ao consórcio INFRAMÉRICA o direito de exploração por 30 anos (Pessoa, 2015). 
Em sua concepção inicial, o projeto consistia em "aeroporto-cidade", intencionalmente planejado para se configurar com um novo polo urbano na RM Natal.

Conforme Almeida \& Vidal (2015, p. 359):

Segundo notícia divulgada na imprensa local a obra do Aeroporto foi iniciada em 2003, e em 2009 já havia consumido recursos da ordem de R \$130 milhões, disponibilizados pelo Governo Federal através do Plano de Aceleração do Crescimento (PAC). Em 2009, confirmavam-se apenas $54 \%$ do projeto concluídos [...]. Essas obras do empreendimento foram coordenadas pela Infraero e o custo, até o final, estimado em mais ou menos R 150 milhões.

O debate em torno do projeto destacava a sua "grande escala" enquanto fator capaz de acelerar o processo de metropolização de Natal. Esperava-se a competição regional com foco no maior dinamismo da RMN em comparação com as demais metrópoles nordestinas - Fortaleza e Recife, principalmente -(Clementino \& Ferreira, 2015; Freire et al., 2015).

0 fato é que o equipamento possui posição estratégica na RMN, o que possivelmente poderia redimensionar "tendências e fluxos, tanto de negócios quanto de pessoas no âmbito interno da RMN e do próprio Estado do Rio Grande do Norte" (Almeida \& Vidal, 2015, p. 361).

Os impactos socioeconômicos do Aeroporto Internacional de São Gonçalo do Amarante, enquanto um grande equipamento urbano-regional, tendiam a refletir de modo aprofundado na melhoria da qualidade de vida da população. Tal melhoria resultaria, diretamente, da ampliação da oferta de empregos e de serviços relacionados à atividade aeroportuária e também da distribuição de renda (FADE, 2007).

Com a formalização da concessão, os atores que se percebiam diretamente envolvidos com o projeto assinaram um protocolo de intenções, estabelecendo a criação de uma comissão tripartite para coordenar ações necessárias à implantação do aeroporto internacional, a qual era composta por governo do Rio Grande do Norte, prefeitura de São Gonçalo do Amarante e o consórcio INFRAMÉRICA. Os entes estadual e municipal referidos estabeleceram compromisso voltado à conclusão dos acessos ao aeroporto, devendo, ainda, instalar redes de esgoto, telefone e energia antes dos terminais. A despeito dessa aparente pactuação de interesses e do reconhecimento do potencial integrador do projeto, a análise das relações estabelecidas entre os entes demonstra a existência de um caso em que uma obra com caráter urbano-regional se configurou, na verdade, enquanto iniciativa local:

Conforme demonstrado acima, a implantação do Projeto do Aeroporto de São Gonçalo do Amarante se deu em meio a uma série de indefinições, redefinições, conflitos e negociações, culminando com a entrada em cena de agentes do mercado. Por se tratar de um investimento de importância regional, observa-se uma aparente homogeneidade de atuação das lideranças políticas locais em torno do projeto, configurando-se ações pactuais que visam à conclusão do projeto e à consolidação do aeroporto (Almeida \& Vidal, 2015, p. 361).

Com relação aos benefícios globais do referido aeroporto, o Quadro 1, extraído de estudo ${ }^{7}$ realizado pela FADE (2007), estabelece uma relação de possíveis benefícios por setor.

No plano Natal Metrópole 2020 foram delineadas algumas recomendações relacionadas ao processo de implementação do Aeroporto Internacional de São Gonçalo do Amarante, uma vez que tal equipamento urbano-regional pressupõe uma articulação vertical e horizontal entre estado e municípios que compõem a Região Metropolitana de Natal, dado que todos sofrem impactos diretos e/ou indiretos do referido equipamento.

Dentre as recomendações podem ser citadas: (i) elaborar um plano de gestão e articulação política e financeira

\footnotetext{
${ }^{7}$ O plano Natal Metrópole 2020 apresenta um conjunto de ações e projetos estratégicos para a RMN, visando à "construção de uma metrópole melhor organizada no seu ordenamento territorial, com seus ricos, mas frágeis recursos naturais bem preservados, com uma base econômica dinâmica e integrada por atividades viáveis e apresentando um quadro social mais justo" (FADE, 2007, p. 5, produtos 5 e 6). Os projetos e ações estratégicas foram enquadrados nos seguintes eixos: a) territoriais estratégicos; b) desenvolvimento social; c) desenvolvimento econômico e criação de emprego; e d) preservação do meio ambiente metropolitano. Os referidos eixos contemplavam propostas nas áreas de (re)ordenamento territorial, mobilidade fundiária, monitoramento de grandes projetos urbanos - com destaque para o Aeroporto Internacional de São Gonçalo do Amarante -, ciência, tecnologia e inovação, habitação, serviços educacionais e de saúde, redução de pobreza e inserção produtiva, segurança alimentar, produção de agroenergéticos, cadeias e arranjos produtivos, turismo, emprego e renda, saneamento ambiental etc.
} 
Quadro 1 - Região Metropolitana de Natal - Benefícios globais do Aeroporto Internacional de São Gonçalo do Amarante (RN)

\begin{tabular}{|c|c|}
\hline Setores & Benefícios \\
\hline Turismo & Aumento da capacidade receptiva do estado \\
\hline Indústria & Facilidade de acesso a novos mercados \\
\hline Imóveis & Valorização imobiliária do estado \\
\hline Governo & Aumento da arrecadacã̃o e dos níveis de emprego \\
\hline Serviço & Crescimento do setor de serviços \\
\hline Comércio & Acesso a novos mercados fornecedores e compradores \\
\hline Região & Redução da duraçã̃o de voos \\
\hline Cidade & $\begin{array}{l}\text { Melhoria da infraestrutura urbana de transporte, comunicacã̃o } \\
\text { e educacá̃o tecnológica etc. }\end{array}$ \\
\hline Estado & Desenvolvimento socioeconômico \\
\hline
\end{tabular}

Fonte: Elaboração dos autores, a partir de FADE (2007), Produto 9, Volume 2.

em parceria com a Infraero, com vistas a integrar o poder público (nos diferentes níveis), com o objetivo de promover ações coordenadas de curto, médio e longo prazo, na perspectiva de garantir o adequado funcionamento do empreendimento; (ii) viabilizar a inserção do aeroporto na preocupação cotidiana do planejamento estadual e ação política, de maneira a possibilitar a negociação de projetos econômicos essenciais à operacionalização do empreendimento; e (iii) promover a consolidação dos acordos (com a Infraero, prefeituras de Natal, CearáMirim, São Gonçalo, Macaíba,) de modo que sejam cumpridas as normas de uso do solo no entorno, como restrições quanto à habitações, escolas, hospitais, indústrias etc. (FADE, 2007).

No contexto de implantação do equipamento, a Prefeitura Municipal de São Gonçalo buscou formas de ampliação dos benefícios futuros, mas apenas em nível local. Nesse sentido, realizou cursos de idiomas no município, responsabilizando-se, ainda, pela iluminação do acesso norte ao aeroporto. Para além do município sede do equipamento, os demais entes locais não demonstraram articulação em torno do interesse comum. Assim, apesar de o projeto impactar o espaço metropolitano, não foram observadas articulações com vistas a um projeto de governança metropolitana que incluísse as transformações esperadas com o aeroporto, além disso, também não foram consideradas ações consorciadas entre os municípios diretamente impactados, notadamente Natal, Parnamirim e São Gonçalo do Amarante.

0 exemplo do processo de implementação do Aeroporto Internacional de São Gonçalo do Amarante ilustra o predomínio de um padrão de planejamento e gestão na RMN que se caracteriza pela realização de projetos que possuem impacto metropolitano mas cuja implementação ocorre a partir de um esforço local, por meio do desenvolvimento de ações isoladas e com pouca ou nenhuma articulação entre os entes metropolitanos. Ou seja, o aeroporto internacional atua em uma base escalar nacional-global e local, não tendo sido capaz de envolver, entretanto, as escalas regional-metropolitana e local.

É preciso denotar que compor uma RM pressupõe não apenas benefícios mas, sobretudo, a existência de capacidades diversas para discutir e tratar problemas comuns, a partir de ações articuladas em uma perspectiva interescalar. Na ausência dessa capacidade, a tendência é o predomínio de práticas locais individualizadas que concorrem para a permanência e, às vezes, para o agravamento de problemáticas que afetam mais de um município concomitantemente. Tal cenário, por sua vez, ainda impera entre os municípios que formam a RMN, inexistindo bases concretas para que se afirme a configuração de um planejamento, de fato, metropolitano.

Diante do exposto, observamos que a RMN convive com problemas financeiros, político-partidários, institucionais e sociais que impactam diretamente na sua capacidade de desenvolver ações cooperadas visando a construção e implementação de uma agenda comum. A partir das discussões realizadas, questionamos: o esvaziamento de soluções políticas de modo articulado não estaria ligado, também, a uma "invisibilidade" do território metropolitano-local?

Desse modo, novos arranjos cooperativos só serão possíveis se existir um ambiente institucional, uma nova capacidade de investimentos e uma Política Escalar que, de fato, internalize o investimento na forma de promoção social e urbana. 0 problema fundante está calcado na falta de uma identidade territorial coletiva que se expresse por meio de laços estáveis que gerem confiança e que sejam capazes de superar interesses apenas locais, o que poderá contribuir para a redução do distanciamento entre a metrópole formal e a metrópole funcional. 


\section{Considerações finais}

Ao iniciarmos este artigo com a questão local-regional-metropolitana objetivamos reafirmar, na pauta de discussões sobre as Regiões Metropolitanas, a "questão escalar". Conforme observamos, existem duas tendências ligadas ao tema metropolitano brasileiro, quais sejam: certo progressivismo no amadurecimento do aparato legal voltado às metrópoles e a manutenção de um campo de disputa mais institucional do que efetivamente territorial.

A legislação - federal e estadual - passou a acomodar uma agenda também urbana ao abordar a criação de territórios supralocais como espaços de convergência de temas de "interesse comum" que são, via de regra, interesses urbanos. Desse modo, retornamos à preocupação de uma Política Urbana que revela uma Política Metropolitana pela agregação de municípios mesmo que - e este é o detalhe mais importante - não integrados territorialmente.

Os planos, programas e projetos, nesse sentido, tendem a refletir e ampliar essa dupla tensão (avançar e estagnar) ao privilegiar ações ora de forte conteúdo local (saneamento, mobilidade intraurbana e moradia), ora ações nacionais e regionais (aeroportos, portos, rodovias etc.).

No caso da RMN, a busca pela captura de planos e projetos se mostra ainda fortemente concentrada no campo da disputa política - competividade por fazer e financiar algo, mesmo que na ausência de um debate territorial. Assim, as obras e intervenções físico-territoriais que surgem parecem minimizar o aparato regulador do Urbano e do Metropolitano (Planos Diretores e Planos de Desenvolvimento Metropolitano), valorizando, na maioria dos casos, a força do agente político municipal (o prefeito ou o governador), inclusive com evidências de disputa política no interior da Assembleia Legislativa.

Tal quadro indica a fragilidade (se não a ausência) de ferramentas políticas, técnicas e sociais para enfrentar os problemas "de interesse comum". Além disso, a frágil relação entre os atores sociais e políticos demonstra a inexistência de uma governança colaborativa, a qual poderia consolidar um modelo de gestão democrática pautada na cooperação entre as esferas de governo, mas também em novas redes de cooperação e colaboração, centradas na participação da sociedade civil e do mercado. Diante dessa ausência, observamos que a partilha de responsabilidades é esquecida, impedindo o estabelecimento de uma agenda positiva, que aborde adequadamente a questão escalar.

De projeto a projeto, a questão escalar e o metropolitano como entidade político-institucional continuam subsumidos, o que sinaliza para a permanência de disputas pautadas mais pela capacidade individual (local) de atrair investimentos do que como resultante de uma construção coletiva por parte dos entes que compõem a RMN.

Entretanto, é importante destacar que nem tudo estabelece um "regime de manutenção" ou de estagnação, posto que entendemos que a atração dos investimentos em si significa que o território ainda conta para manter o tema metropolitano vivo no campo político. Ora, se esse território institucional é, repetidamente, expandido, mesmo que sob alegações de interesse comum que não se efetivam, é sinal de que há espaço, sim, para arranjos, acordos e modelos de cooperação. Tal afirmação se dá em função da existência, ainda que incipiente, de bases de governança e gestão metropolitana, as quais precisam ser fortalecidas a partir de instrumentos que favoreçam ações coordenadas e cooperadas.

Desse modo, vemos que, apesar dos recentes avanços normativos, há, ainda, um campo fértil para o debate local-regional-metropolitano e suas formulações escalares. É preciso traduzir, na prática, a esfera de disputa política e institucional em uma esfera de disputa também territorial, a qual deve priorizar a formulação de agendas, de novos planos e projetos que considerem o território vivido e usado. Insistimos que a Metrópole ainda pode auxiliar nessa tarefa.

\section{Referências}

Almeida, L. S. B., \& Vidal, S. M. S. C. (2015). Pacto socioterritorial: arena, atores e processo decisório na Região Metropolitana de Natal (RN). In M. L. M. Clementino, \& A. L. Ferreira (Eds.), Natal: transformações na ordem urbana. Rio de Janeiro: Letra Capital Editora.

Ansell, C., \& Gash, A. (2007). Collaborative governance in theory and practice. Practice Journal of Public Administration Research and Theory Advance, 18(4), 543-571. http:// dx.doi.org/10.1093/jopart/mum032.

Borja, J., \& Castells, M. (2004). Local y global: la gestión de las ciudades en la era de la información (7. ed.). Madrid: Tauru. 
Brandão, C. A., Costa, E. J. M., \& Alves, M. A. S. (2006). Construir o espaço supralocal de articulação socioprodutiva e das estratégias de desenvolvimento: os novos arranjos institucionais. In C. C. Diniz, \& M. Crocco (Eds.), Economia regional e urbana: contribuições teóricas recentes. Belo Horizonte: EdUFMG.

Brasil. (1967, 24 de janeiro ). Constituição da República Federativa do Brasil de 1967. Brasília: Diário Oficial da União. Recuperado em 20 de dezembro de 2016, de http://www. planalto.gov.br/ccivil_03/constituicao/constituicao67.htm

Brasil. (1973, 11 de junho). Lei Complementar no 14, de 8 de junho de 1973. Estabelece as regiões metropolitanas de São Paulo, Belo Horizonte, Porto Alegre, Recife, Salvador, Curitiba, Belém e Fortaleza (pp. 5585). Brasília: Diário Oficial da União.

Brasil. (1988, 5 de outubro). Constituição da República Federativa do Brasil de 1988. Brasília: Diário Oficial da União.

Brasil. (2005, 7 de abril). Lei no 11.107, de 6 de abril de 2005. Dispõe sobre normas gerais de contratação de consórcios públicos e dá outras providências (pp. 1). Brasília: Diário Oficial da União.

Brasil. (2015, 13 de janeiro). Lei no 13.089, de 12 de janeiro de 2015. Institui o Estatuto da Metrópole, altera a Lei $n^{\circ}$ 10.257, de 10 de julho de 2001, e dá outras providências (pp. 2). Brasília: Diário Oficial da União.

Brenner, N. (2001). The limits to scale? Methodological reflections on scalar structuration. Progress in Human Geography, 25(4), 591-614. http://dx.doi.org/10.1191/030913201682688959.

Brenner, N. (2004). New state space: urban governance and the rescaling of statehood. Oxford: Oxford University Press. http:// dx.doi.org/10.1093/acprof:oso/9780199270057.001.0001.

Brenner, N. (2013). Reestruturação, reescalonamento e a questão urbana. GEOUSP Espaço e Tempo, 33(33), 198-220. http://dx.doi.org/10.11606/issn.2179-0892. geousp.2013.74311.

Clementino, M. L. M., \& Almeida, L. S. (2015). Construção técnico-política de governança metropolitana. Cadernos Metrópole, 17(33), 201-224. http://dx.doi. org/10.1590/2236-9996.2015-3309.

Clementino, M. L. M., \& Ferreira, A. L. (2015). Caminhos para se pensar a metropolização de Natal: questões, hipóteses e referências. In M. L. M. Clementino, \& A. L. Ferreira (Eds.), Natal: transformações na ordem urbana. Rio de Janeiro: Letra Capital Editora.
Ferreira, G. D. (2005). Políticas estaduais de desenvolvimento e guerra fiscal (Dissertação de mestrado). Instituto de Economia, Universidade Estadual de Campinas, Campinas.

Freire, F. H. M. A., Gonzaga, M. R., \& Ojima, R. (2015). Dinâmica demográfica da Região Metropolitana de Natal. In M. L. M. Clementino, \& A. L. Ferreira (Eds.), Natal: transformações na ordem urbana. Rio de Janeiro: Letra Capital Editora.

Frey, K. (2012). Abordagens de governança em áreas metropolitanas da América Latina: avanços e entraves. urbe. Revista Brasileira de Gestão Urbana, 4(1), 87-102. http://dx.doi.org/10.1590/S2175-33692012000100007.

Fundação de Apoio ao Desenvolvimento - FADE. Universidade Federal de Pernambuco. Universidade Federal do Rio Grande do Norte. (2007). Tendências, visão de futuro e diretrizes do Plano Estratégico Natal Metrópole 2020: plano Estratégico de Desenvolvimento Sustentável para Região Metropolitana de Natal. Natal: Governo do Estado do Rio Grande do Norte.

Garson, S. (2005). Capacidades e limites à participação dos municípios no financiamento do desenvolvimento urbano. In Anais do Encontro Nacional da ANPUR (pp. 11). São Paulo: ANPUR.

Garson, S. (2009). Regiões metropolitanas: por que não cooperam? Rio de Janeiro: Letra Capital.

Gottdiener, M. (2010). A produção social do espaço urbano. São Paulo: Edusp.

Grau, E. R. (1972). Aspectos institucionais das áreas metropolitanas. In Anais do II Curso de Planejamento Urbano e Local. Brasília: Ministério do Interior, SERFHAU.

Harvey, D. (2006). A produção capitalista do espaço. São Paulo: Annablume.

McGee, T. (2010). Construindo uma governança urbana colaborativa. In E. Castro, \& M. Wojciechowski (Eds.), Inclusão, colaboração e governança urbana: perspectivas brasileiras. Belo Horizonte: PUC Minas.

Neves, R. R., Velloso, R., \& Wojciechowski, M. J. (2010). Capacidade Institucional: planejamento e gestão para governança metropolitana colaborativa. In E. Castro, \& M. Wojciechowski (Eds.), Inclusão, colaboração e governança urbana: aprendizagem e capacidade institucional. Belo Horizonte: PUC Minas.

Pessoa, Z. S. (2015). Organização e estrutura social da Região Metropolitana de Natal: permanências e mudanças entre 2000 e 2010. In M. L. M. Clementino, \& A. L. Ferreira 
(Eds.), Natal: transformações na ordem urbana. Rio de Janeiro: Letra Capital.

Raffestin, C. (1993). Por uma geografia do poder. São Paulo: Ática.

Reis, F. W. (1994). Governabilidade e instituições políticas. In J. P. R. Velloso (Eds.), Governabilidade, sistema político e violência urbana. São Paulo, José Olímpio.

Rio Grande do Norte. (1997, 6 de fevereiro). Lei Complementar no 152 de 16 de janeiro de 1997. Institui a Região Metropolitana do natal e dá outras providências (pp. 8-9). Natal: Diário Oficial do Estado, no 8.945.

Rio Grande do Norte. (2002, 11 de janeiro). Lei Complementar $n-221$, de 10 de janeiro de 2002. Altera dispositivos da Lei Complementar no 152, de 16 de janeiro de 1997, que dispõe sobre a Região Metropolitana de Natal, e dá outras providências (pp. 1). Natal: Diário Oficial do Estado, no 10.158 .

Rio Grande do Norte. (2005, 2 de dezembro). Lei Complementar no ${ }^{-} 315$, de 30 de novembro de 2005. Altera dispositivos da Lei Complementar no 152, de 16 de janeiro de 1997, que dispõe sobre a Região Metropolitana de Natal, e dá outras providências (pp. 1). Natal: Diário Oficial do Estado, no 11.119 .

Rio Grande do Norte. (2009, 23 de julho). Lei Complementar no 391, de 22 de julho de 2009. Altera dispositivo da Lei Complementar no 315, de 30 de novembro de 2005, que dispõe sobre a Região Metropolitana de Natal, e dá outras providências (pp. 41). Natal: Diário Oficial do Estado, no 12.012 .

Rio Grande do Norte. (2013, 26 de fevereiro). Lei Complementar $n^{\circ}$ 485, de 25 de fevereiro de 2013. Altera dispositivo da Lei Complementar no 391, de 22 de julho de 2009, que dispõe sobre a Região Metropolitana de Natal, e dá outras providências (pp. 22). Natal: Diário Oficial do Estado no 12.897.

Rio Grande do Norte. (2015a, 28 de julho). Lei Complementar $n^{\circ}$ 540, de 27 de julho de 2015. Altera dispositivo da Lei Complementar no 485, de 25 de fevereiro de 2013, que dispõe sobre a Região Metropolitana de Natal, e dá outras providências (pp. 1). Natal: Diário Oficial do Estado, nำ 13.487.

Rio Grande do Norte. (2015b, 29 de dezembro). Lei Complementar no 559 de 28 de dezembro de 2015. Altera dispositivo da Lei Complementar no 540, de 27 de julho de 2015, que dispõe sobre a Região Metropolitana de Natal, para incluir os Municípios de Arês e Goianinha (pp. 1). Natal: Diário Oficial do Estado, no 13.591.

Santos, M. (1996). A natureza do espaço: técnica e tempo, razão e emoção. São Paulo: Hucitec.

Santos, M. (2000). Território e sociedade: entrevista com Milton Santos. São Paulo: Perseu Abramo.

Santos, M. (2004). Testamento Intelectual: entrevistado por Jesus de Paula Assis e Maria Encarnação Sposito. São Paulo: Editora UNESP.

Secretaria de Estado do Meio Ambiente e dos Recursos Hídricos - SEMARH. (2012). Relatório síntese: plano estadual de gestão integrada de resíduos sólidos do Rio Grande do Norte - PEGIRS/RN Natal (RN). Natal: SEMARH. Recuperado em 20 de agosto de 2016, de http://adcon.rn.gov.br/ ACERVO/semarh/doc/DOC000000000020200.PDF

Smith, N. (1988). Desenvolvimento desigual: natureza, capital e a produção de espaço. Rio de Janeiro: Bertrand Brasil.

Smith, N. (2000). Contornos de uma política espacializada: veículos dos sem-teto e produção de escala geográfica. In A. A. Arantes (Ed.), O espaço da diferença. Campinas: Papirus.

Soja, E. (1993). Geografias pós-modernas: a reafirmação do espaço na Teoria Social Crítica. Rio de Janeiro: Jorge Zahar.

Souza, M. A. A. (2006). Recompondo a história da Região Metropolitana: processo, teoria e ação. In C. A. S. Silva, D. G. Freire, \& F. J. G. Oliveira. Metrópole: governo, sociedade e território. Rio de Janeiro: DP\&A/FAPERJ.

Souza, M. L. (2013). Os conceitos fundamentais da pesquisa sócio-espacial. Rio de Janeiro: Bertrand Brasil.

Vainer, C. (2002). As escalas do poder e o poder das escalas: o que pode o poder local? Cadernos do IPPUR, 16(1), 13-32.

Recebido: Maio 01, 2017

Aprovado: Dez. 15, 2017 